\section{Conclusion}

Early initiation of novel treatments (thrombolytics and neuroprotectants) in patients with acute ischaemic stroke is likely to improve the outcome for these patients. However, both of these types of treatment must be given as early as possible for optimal effect and safety. While the administration of thrombolytics requires a definitive diagnosis, it is hoped that in the future, it may be possible to treat patients with neuroprotective treatments before the patient arrives in hospital. In order for this to happen, emergency service personnel should be able to evaluate a stroke patient promptly, and be aware of the need to treat stroke as an emergency. Additionally, the general public needs to be educated to recognise the signs and symptoms of stroke and to react quickly to them by calling the emergency number.

1 Thorvaldsen P, Asplund K, Kuulasmaa K, et al. Stroke incidence, case fatality and mortality in the WHO MONICA project. World Health Organization monitoring trends and project. World Health Organization monitoring trends and determinants

2 Spitzer K, Becker V, Thie A, et al. The Hamburg stroke data bank: goals, design and preliminary results. $\mathcal{F}$ Neurol 1989 ; 236:139-44

3 Adams HP Jr, Brott TG, Furlan AJ, et al. Guidelines for thrombolytic therapy for acute stroke: a supplement to the guidelines for the management of patients with acute ischemic stroke. A statement for healthcare professionals from a special writing group of the Stroke Council, American Heart Association. Stroke 1996;27:1711-18.

4 Solis O, Robertson G, Taveras J, et al. Cerebral angiography in acute cerebral infarction. Rev Interam Radiol 1979;2:1925.

5 Allen C. Clinical diagnosis of acute stroke syndrome. $Q \mathcal{F}$ Med 1983;42:515-23.

6 Poungvarin N, Viriyavejakul A, Komontri C. Siriraj stroke score and validation study to distinguish supratentorial score and validation study to distinguish supratentorial intracerebral.

7 Jafar J, Crowell R. Focal ischemic thresholds. In: Wood J, ed. Cerebral blood flow. New York: McGraw-Hill, 1987: 449-57.

8 Hacke W, Stingele R, Steiner T, et al. Crititcal care of acute ischemic stroke. Intensive Care Med 1995;21:856-62.

9 Astrup J, Siesjö BK, Symon L. Thresholds in cerebral ischemia-the ischemic penumbra. Stroke 1981;12:723-5.

10 Caplan L. Reperfusion of ischemic brain: why and why not. In: Hacke W, del Zoppo G, Hirschberg M, eds. Thrombolytic therapy in acute ischemic stroke. Berlin: Springer, 1991:
$37-45$.
11 Adams HJ, Brott T, Furlan A, et al. Guidelines for thrombolytic therapy for acute stroke: a supplement to the guidelines for the management of patients with acute ischemic stroke. A statement for healthcare professionals from a special writing group of the stroke council, American Heart Association. Stroke 1996;27:1711-8.

12 The RANTTAS Investigators. A randomized trial of tirilazad mesylate in patients with acute stroke (RANTTAS). Stroke 1996;27:1453-8.

13 The European Ad Hoc Consensus Group. European strategies for early intervention in stroke. Cerebrovascular Disease 1996;6:315-24.

14 Alberts M, Perry A, Dawson D, et al. Effects of public and professional education on reducing the delay in presentation and referral of stroke patients. Stroke 1992;23.352-6.

15 Kothari R, Barsan W, Brott T, et al. Frequency and accuracy of prehospital diagnosis of acute stroke. Stroke 1995;26: 937-41.

16 Lott C, Hennes H, Dick W. Prehospital diagnosis in stroke patients-differentiation between cerebral ischemic events and hemorrhage. Intensive Care Med 1996;22 (suppl 1):S96.

17 The American-Canadian Co-Operative Study Group. Presantine aspirin trial in cerebral ischaemia. Part II: endpoint results. Stroke 1985;16:406-15.

18 Bronstein KS, Chadwick LR. Ticlopidine hydrochloride: its current use in cerebrovascular disease. Rehabilitation Nursing 1994;19:17-20.

19 Hacke W, Kaste M, Fieschi C, et al. Intravenous thrombolysis with recombinant tissue plasminogen activator for acute sis with recombinant tissue plasminogen activator for acute Stroke Study (ECASS). $\mathscr{f} A M A$ 1995;274:1017-25.

20 National Institute of Neurological Disorders and Stroke rt-PA Stroke Study Group. Tissue plasminogen activator for acute ischaemic stroke. $N$ Engl f Med 1995;333:1581-7.

21 Hommel M, Biossel P, Cornu E, et al. for the MAST Study Group. Termination of trial of streptokinase in severe acute ischaemic stroke. Lancet 1994;345:57.

22 Multicenter Acute Stroke Trial Italy (MAST-I). Randomized controlled trial of streptokinase, aspirin and combination of both in treatment of acute ischaemic stroke. Lancet 1995;346:1514.

23 Donnan GA, Davis SM, Chambers BR, et al. Trials of streptokinase in severe acute ischaemic stroke. Lancet 1995;345: 578-9.

24 Walghren NG, MacMahon DG, De Keyser J, et al for the INWEST Study Group. Intravenous Nimodipine West European Stroke Trial of nimodipine in the treatment of acute ischaemic stroke. Cerebrovascular Disease 1994;4: acute ischae
$197-203$.

25 Muir KW, Lees KR. Clinical experience with excitatory Muir KW, Lees KR. Clinical experience with excitato

26 MacDonald JW, Silverstein FS, Johnston MV. Magnesium reduces N-methyl-D-aspartate (NMDA)-mediated brain injury in perinatal rats. Neurosci Lett 1990;109:234-8.

27 Young W, Wojack JC, De Crescito W. 21-aminosteroid reduces ion shift in oedema in the rat middle cerebral occlusion model of regional ischaemia. Stroke 1988;9: 1013-19.

28 RANTTAS Investigators. Randomised trial of tirilizad in acute stroke (RANTTAS) by the RANTTAS investigators, the neuroclinical centre, University of Charlottesville, VA, and the North American RANTTAS participants. Stroke 1996;27:164 (abst).

29 Diener $H$, Hacke W, Hennerici $M$. Lubeluzole in acute ischemic stroke: a double-blind placebo controlled phase II trial. Stroke 1996;27:76-81.

\title{
Recent advances in the acute management of ischaemic stroke
}

\author{
Michael Roberts, Geoff Hughes
}

\section{Department of Emergency Medicine, Wellington Hospital, Riddiford Street, Wellington, New Zealand \\ M Roberts \\ G Hughes}

Correspondence to: Mr Roberts, Registrar (e-mail: phillifam@xtra.co.nz).
Stroke is the third commonest cause of death and the commonest cause of adult disability in the western world. Approximately 1.5 million patients in Europe and America suffer acute stroke each year ${ }^{1}$ and $85 \%$ of these are ischaemic. This is an enormous burden to patients, their families, and also to health care systems. Although the incidence of stroke has declined in recent years, ${ }^{2}$ it is likely to become more prevalent in the future as the population ages.

Recent licensing of the thrombolytic agent, recombinant tissue plasminogen activator (rtPA) in the United States for treatment of selected stroke patients has focused attention on active stroke management. However the restoration of blood flow to ischaemic brain is only one of several approaches currently being investigated to improve stroke outcome. Advances in the understanding and manipulation of the cellular derangements which occur in the ischaemic brain offer other possibilities for active treatment. Development of investigations which differentiate between ischaemic and infarcted tissue will allow new therapies to be directed towards those patients most likely to benefit. 


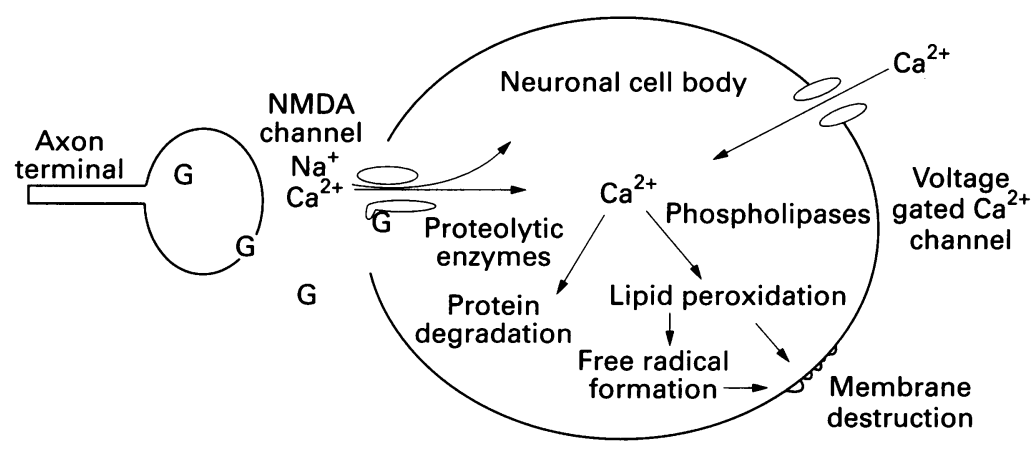

Figure 1 Mechanism of neuronal death during focal brain ischaemia. $\mathrm{Ca}^{2+}=$ intracellular free calcium ion; $G=$ glutamate; $N a^{+}=$oxidised sodium ion; $N M D A=$

$N$-methyl-D-aspartate. (Reproduced from $G W$ Albers. Rationale for early intervention in acute stroke. Am J Cardiol 1997;80(4C):4D-10D with permission from Excerpta Medica Inc.) ity in the hours following stroke. This can cause haemorrhagic transformation of infarcted tissue, varying in severity from small petechiae to large and clinically significant parenchymal haematomas. Haemorrhagic transformation is commonest in large volume lesions and in those of cardioembolic origin. ${ }^{56}$

\section{Imaging in acute stroke}

Computed tomography is still considered the best tool to differentiate ischaemic from haemorrhagic stroke at the time of presentation, ${ }^{7}$ a necessity if thrombolytics or antithrombotics are used. ${ }^{8}$ Identification of hypodense areas on early computed tomograms, suggesting substantial areas of infarction, ${ }^{9}$ also helps to identify those lesions most likely to undergo haemorrhagic transformation. These patients are the ones most likely to suffer intracranial haemorrhage if thrombolysed. ${ }^{10}$

While magnetic resonance imaging (MRI) is reported to show ischaemic changes earlier than can be demonstrated by computed tomography, it is less useful in making the essential distinction between ischaemic and haemorrhagic stroke. It is also less available, more expensive, and more time consuming.

Within these constraints the newer techniques of MRI and MR spectroscopy with diffusion weighted imaging allow differentiation between infarcted and ischaemic tissue. ${ }^{11}$ When these imaging modalities are more widely available they will permit patient selection for thrombolysis based on identification of potentially salvageable tissue rather than by application of a rigid time interval from symptom onset. The latter may exclude patients who could still benefit from treatment and includes, and exposes to the risk of haemorrhage, some patients with little salvageable tissue (see figs 2,3 , and 4 ).

\section{Treatment options}

Potential treatments may be categorised by mechanism of action. Interventions such as thrombolytics and antithrombotics, which aim to improve blood supply to affected tissue, are distinguished from neuroprotective agents which aim to reduce the damage caused by ischaemia. An alternative classification differentiates simple, often inexpensive, interventions, which can be widely used after minimal investigation from treatments such as thrombolysis, which are expensive and can only be used on a relatively small group of patients after intensive investigation.

The first group may produce considerably smaller percentage improvements in outcome but their broad applicability may result in a greater overall benefit to populations. Recognition of these differences ${ }^{12}$ and the impact they should have on trial design has been clearly defined. ${ }^{13}$

Many potential treatments require prompt institution if they are to be helpful, and education of the public and the medical profession to expedite hospitalisation of patients with stroke will become more important. Management of patients by dedicated stroke teams in their own units is also of proved benefit. ${ }^{14}$ 


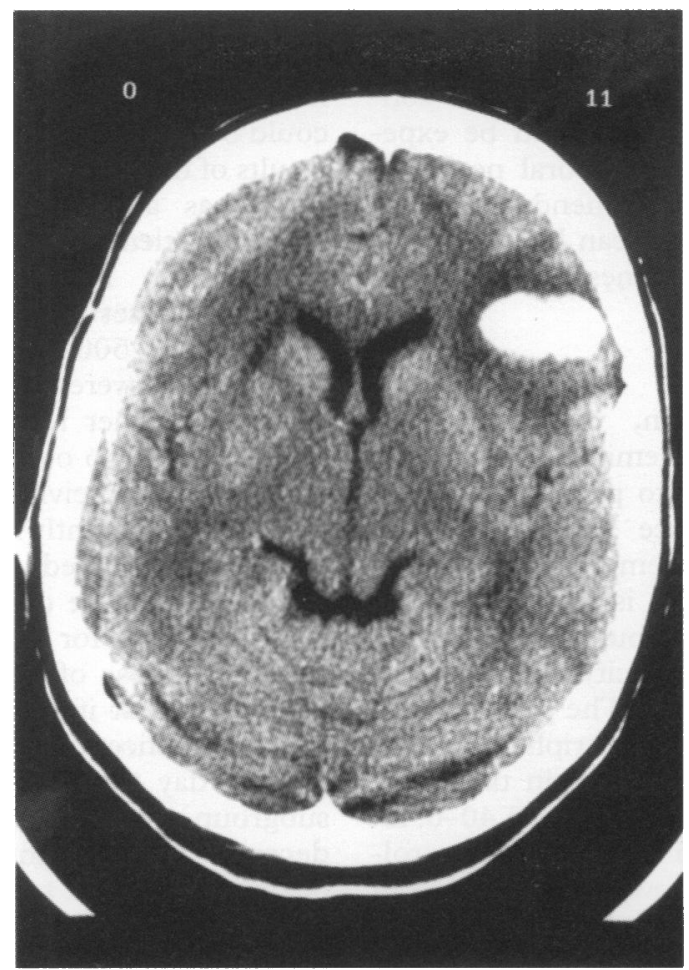

Figure 2 Computed tomogram showing acute haemorrhagic stroke with surrounding oedema at four hours after onset of symptoms.

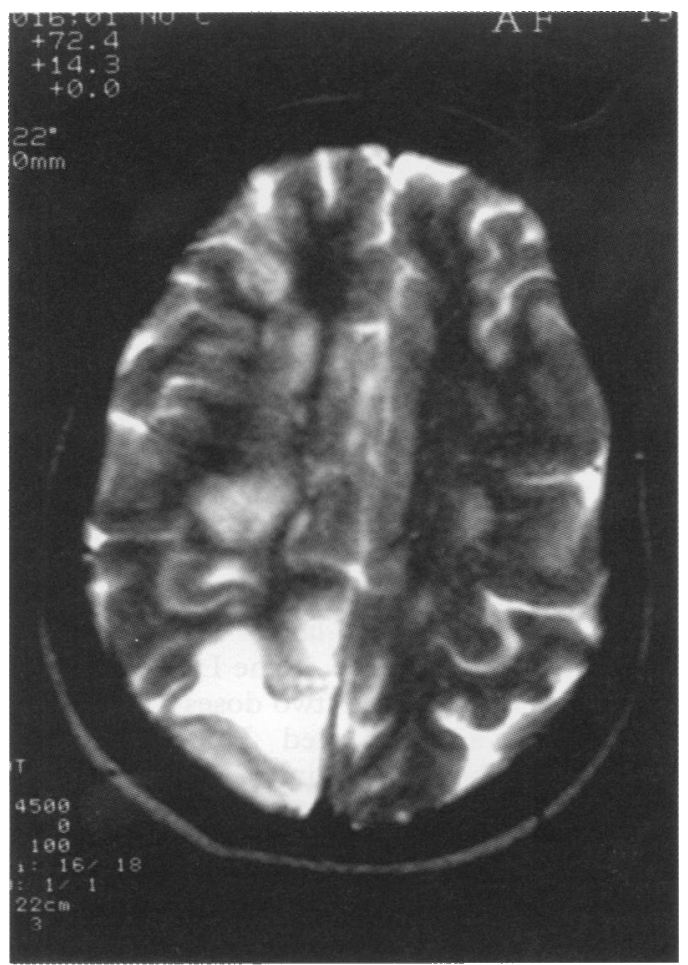

Figure $3 T 1$ weighted MRI scan showing occipital infarct at eight hours after onset of symptoms.

\section{General measures}

Airway protection in patients with decreased level of consciousness or absent gag reflex, correction of hypoxaemia and treatment of hypoglycaemia or hyperglycaemia are all essential. Relevant blood tests include full blood count to identify hyperviscosity states and thrombocytopenia and coagulation studies to exclude coagulopathy. Measurement of the erythrocyte sedimentation rate may identify a

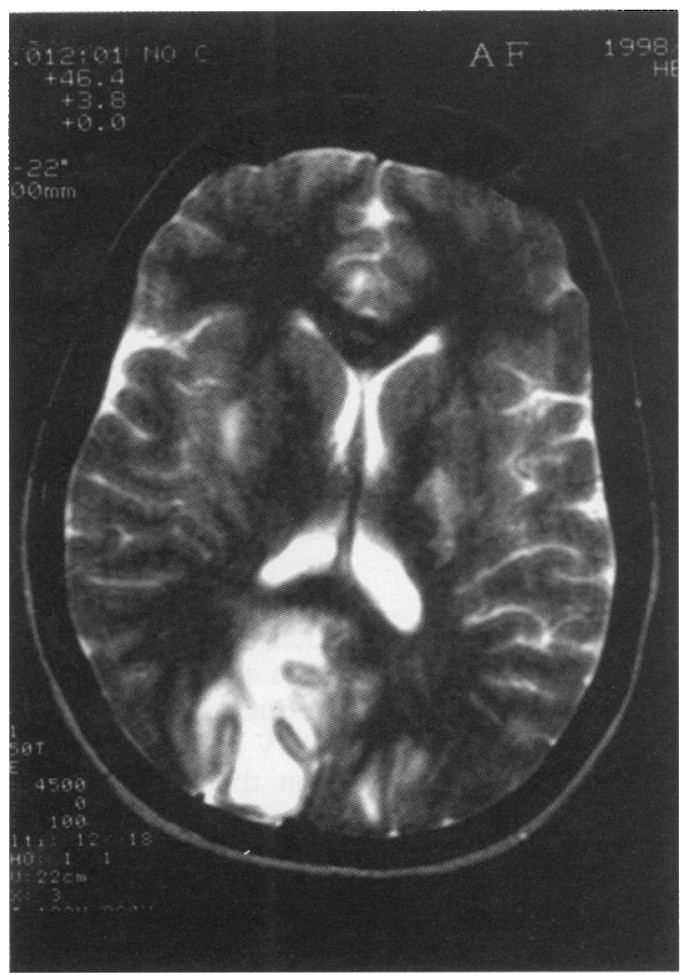

Figure 4 T2 weighted MRI scan showing occipital infarct at eight hours after onset of symptoms.

vasculitis. Arterial blood gas estimation should be performed if respiratory function may be compromised. An electrocardiogram should be obtained to identify a possible cardiac cause for stroke; atrial fibrillation and acute myocardial infarction are both significant risk factors. Echocardiography may demonstrate valvar vegetations or mural thrombus if cardioembolic stroke is suspected. Basic nursing care such as preservation of skin integrity by protection of pressure areas should receive attention from the time of arrival at hospital. Brain injury is temperature sensitive and so treatment of pyrexia and any underlying cause is recommended. ${ }^{15}$

\section{Blood pressure control}

After stroke normal autoregulatory mechanisms fail and cerebral perfusion is directly related to mean arterial blood pressure. At present there is no evidence from randomised controlled trials that lowering blood pressure at any level is beneficial. ${ }^{16}$ Current recommendations are that hypertension should not be treated unless severe (systolic $>220 \mathrm{~mm} \mathrm{Hg}$ or diastolic $>130 \mathrm{~mm} \mathrm{Hg}$ ) so that unnecessary cerebral hypoperfusion can be avoided. ${ }^{15}$ However hypertension is a risk factor for haemorrhagic transformation and trials of thrombolytic agents have set a lower threshold for treatment or exclusion. In the National Institute of Neurological Disorders and Stroke (NINDS) trial of rt-PA, for example, patients whose blood pressure could not easily be brought below $185 \mathrm{~mm} \mathrm{Hg}$ systolic were excluded. ${ }^{17}$ It must be emphasised that these varied parameters for treatment are not based on evidence from controlled trials. These studies remain to be performed. 
No studies have investigated the importance of raising blood pressure in patients who are hypotensive at presentation. Theoretical considerations suggest that this should be expedited in order to improve cerebral perfusion pressure and this is the recommendation of the Stroke Council of the American Heart Association in their guidelines on stroke management. ${ }^{15}$

\section{Haemodilution}

Intentional haemodilution, which may be isovolaemic or hypervolaemic, is known to improve oxygen delivery to peripheral tissues and has been used since the $1960 \mathrm{~s}$ as a treatment for acute ischaemic stroke. As the packed cell volume (PCV) is reduced oxygen delivery increases to a peak but then falls as the loss of oxygen carrying capacity outweighs the reduction in blood viscosity. The peak lies at a PCV of $0.30-0.33$ in normal peripheral tissues but there is evidence that in brain tissue the maximum may be as high as $0.40-0.45$. Formal analysis of the 15 randomised controlled trials available has shown no reduction in early or late case fatality or functional outcome and this once popular treatment is no longer recommended. ${ }^{18}$ However it should be noted that in these studies patients were treated up to 72 hours after onset of symptoms. There is some evidence from animal studies suggesting that haemodilution performed within three hours of cerebral occlusion can significantly alter infarct size. ${ }^{19}$ Further studies are required in this area.

\section{Corticosteroids}

Cerebral oedema is a significant cause of death after stroke both directly by reduction of cerebral perfusion pressure and indirectly by inducing vasospasm. Cerebral oedema may be vasogenic (related to breakdown of the bloodbrain barrier as in tumours) or cytotoxic (related to cell membrane dysfunction as occurs in focal or generalised ischaemia). While corticosteroids have a proved role in the management of vasogenic oedema they are not of value in the predominantly cytotoxic oedema of acute stroke. Meta-analysis of available trials has shown that their use confers no benefit and that there is also possibly a higher fatality rate among patients receiving them. ${ }^{20}$

\section{Antithrombotic and antiplatelet aggregating drugs}

These agents, which are extensively used in the prevention of ischaemic vascular events, have yet to have their role fully established in acute stroke. The rationale for their use is clearthey should help to maintain or improve perfusion to the brain by halting the propagation of thrombus or preventing recurrent thromboembolism. They may also reduce mortality and morbidity by preventing common complications of stroke such as deep vein thrombosis and pulmonary embolism.

Heparin has been used widely in stroke management over the past 50 years. However in the 1994 guidelines on the management of acute ischaemic stroke issued by the American
Heart Association ${ }^{15}$ the available data regarding its efficacy and safety were considered sufficiently unclear that no recommendation could be made about its use. Publication of the results of the International Stroke Trial in early 1997 has added clarification. ${ }^{21}$ A total of 19435 patients with ischaemic stroke were allocated to receive within 48 hours of symptom onset either subcutaneous heparin (at a dose of 5000 or 12500 IU) or placebo. The patients were also allocated, in a factorial design, to either receive aspirin or not. The study showed no overall benefit at six months for patients receiving heparin and demonstrated a significantly higher incidence of major extracranial bleeds, more haemorrhagic strokes, and more deaths or non-fatal strokes within 14 days for those patients allocated to the higher dose of heparin. The investigators concluded that if heparin were to be used in clinical practice the lower trial dose of $5000 \mathrm{IU}$ twice a day should not be exceeded. In this subgroup there was a small but significant decrease of $1.2 \%$ in the incidence of early death or recurrent stroke without a significant increase of serious extracranial bleeds. This has prompted a recommendation for further studies. ${ }^{22}$

Data relating to the efficacy of aspirin were analysed alone and, as previously planned, summated with the results of the Chinese Acute Stroke Trial. ${ }^{23}$ In this investigation 21106 patients with suspected acute ischaemic stroke received within 48 hours of symptom onset either aspirin in a dose of 160 $\mathrm{mg} /$ day or placebo, continued for up to four weeks. Overall there was a small, but significant benefit to treatment with 13 per 1000 fewer dead or dependent in the first weeks and months of follow up.

Low molecular weight (LMW) heparins and heparinoids, both experimentally and clinically, are associated with a lower risk of bleeding than unfractionated heparin. Extensive investigations in prophylaxis of deep vein thrombosis shows them to be more effective and safer than heparin, aspirin, and anticoagulants.

The LMW heparin Nadroparin was used in two doses in the randomised, placebo controlled Hong Kong study. ${ }^{24}$ At six months unfavourable outcomes were reduced from $65 \%$ in a placebo group to $52 \%$ in a low dose treatment group and $45 \%$ in those patients receiving a higher dose of Nadroparin. Further trials are underway as they are for the LMW heparinoid Org 10172 which has shown encouraging results in pilot studies. ${ }^{25}$

\section{Thrombolysis}

A variety of thrombolytic agents have been studied including streptokinase, urokinase, and t-PA using intravenous and intra-arterial routes for administration. Common to all trials is the frustration of finding the benefits of reperfusion partially or totally negated by the increased risk of intracranial haemorrhage.

The high levels of technical involvement associated with the intra-arterial route are responsible for the small number of studies of 
Table 2 The results of the major clinical trials of intravenous thrombolysis so far completed. (Reproduced from $M \mathcal{F}$ Alberts. Hyperacute stroke therapy with tissue plasminogen activator. Am J Cardiol 1997;80(4C):29D-34D with permission from Excerpta Medica Inc)

\begin{tabular}{|c|c|c|c|c|c|}
\hline Study & Drug(s) used & Dose & $\begin{array}{l}\text { Time limit from } \\
\text { stroke case }(h)\end{array}$ & No of patients & Major results \\
\hline $\begin{array}{l}\text { European Cooperative } \\
\text { Stroke Study (ECASS) }\end{array}$ & $t-P A$ & $\begin{array}{l}1.1 \mathrm{mg} / \mathrm{kg} \text {, to } \\
\text { maximum of } 100 \mathrm{mg}\end{array}$ & 6 & 620 & $\begin{array}{l}17.4 \% \text { of patients were enrolled despite major protocol } \\
\text { violations. Analysis of all patients showed no benefit. } \\
\text { Analysis of eligible patients ("target population") } \\
\text { revealed significant modified rank in scale improvement } \\
\text { in favor of t-PA treated patients ( } \mathrm{p}=0.035) ; 20 \% \text { rate of } \\
\text { ICH. }\end{array}$ \\
\hline $\begin{array}{l}\text { National Institute of } \\
\text { Neurological Disorders } \\
\text { and Stroke (NINDS) } \\
\text { rt-PA Stroke Study }{ }^{17}\end{array}$ & $t-P A$ & $\begin{array}{l}0.9 \mathrm{mg} / \mathrm{kg} \text {, to } \\
\text { maximum of } 90 \mathrm{mg}\end{array}$ & $1.5-3$ & 624 & $\begin{array}{l}\text { Compared with placebo group, t-PA treated patients were } \\
\geqslant 30 \% \text { more likely to have minimal or no disability at } 3 \\
\text { months. Symptomatic ICH within } 36 \text { hours of stroke } \\
\text { occurred in } 6.4 \% \text { of } t-P A \text { treated patients and } 0.6 \% \text { of } \\
\text { placebo treated patients }(p<0.001) \text {. }\end{array}$ \\
\hline $\begin{array}{l}\text { Multicenter Acute Stroke } \\
\text { Trial-Europe } \\
\left(\text { MAST-E) }{ }^{28}\right.\end{array}$ & SK & $1.5 \mathrm{MU}^{\star}$ & 6 & 310 & $\begin{array}{l}\text { Stopped early. There was a high frequency of } \\
\text { haemorrhagic events and deaths in SK treated patients. } \\
\text { At } 6 \text { months, survivors in SK group had greater } \\
\text { improvement in function and were less likely to be } \\
\text { severely disabled than placebo treated patients, but } \\
\text { differences were not statistically significant. }\end{array}$ \\
\hline $\begin{array}{l}\text { Multicenter Acute Stroke } \\
\text { Trial-Italy (MAST-I) }{ }^{29}\end{array}$ & SKtaspirin & $\begin{array}{r}1.5 \mathrm{MU} \text { SK; } 300 \\
\mathrm{mg} / \text { day aspirin }\end{array}$ & 6 & 622 & $\begin{array}{l}\text { Stopped early. There was a non-significant reduction in } \\
\text { likelihood of death/disability after treatment with SK. } \\
\text { However, } 10 \text { day mortality and symptomatic ICH were } \\
\text { significantly higher in patients treated with SK. Risk of } \\
\text { early death or bleeding especially high when SK was } \\
\text { combined with aspirin. }\end{array}$ \\
\hline $\begin{array}{l}\text { Australian Streptokinase } \\
\text { Trial (ASK) }\end{array}$ & SK & $1.5 \mathrm{MU}$ & 4 & 340 & $\begin{array}{l}\text { Stopped early. Treatment with SK showed no significant } \\
\text { benefit over placebo. There was a non-significant trend } \\
\text { toward unfavourable outcomes in SK treated patients. }\end{array}$ \\
\hline
\end{tabular}

*Other drugs could be administered at the discretion of the individual investigator. Some patients received heparin

$\mathrm{ICH}=$ intracerebral haemorrhage; $M U$ = million units; $\mathrm{SK}=$ streptokinase; $\mathrm{t}-\mathrm{PA}=$ tissue plasminogen activator.

its efficacy in spite of the theoretical advantage of the lower required dose of thrombolytic. However promising results from the PROACT $\mathrm{trial}^{26}$ using prourokinase by this route are under further investigation in the PROACT 11 trial. $^{27}$

The results of the major clinical trials of intravenous thrombolysis so far completed are summarised in table $2 .^{10} 1728-30$

Clearly the results of the NINDS trial are encouraging with a total of 11-13 extra patients per hundred treated having an excellent outcome with little or no neurological deficit. This is in spite of a $6.4 \%$ rate of intracranial haemorrhage as compared with $0.6 \%$ in the placebo group. Failure of the other trials to show benefit may be for many reasons. Different thrombolytics at different doses were used and treatment was often initiated longer after symptom onset than in the NINDS study where although the exclusion time for treatment was three hours, $50 \%$ of patients were receiving treatment less than 90 minutes after onset of symptoms.

Critics of thrombolysis point out that the 624 patients in the study were selected from over 17000 patients presenting with stroke at the participating hospitals. Most of the exclusions were for late presentation in spite of an education programme aimed to minimise this problem. This suggests that thrombolysis cannot yet be considered a routine treatment, although this may change when the results of further studies (ATLANTIS and ECASS 2) of the efficacy of rt-PA used up to six hours after symptom onset become available.

\section{Neuroprotective agents}

A very large number of agents which might reduce the effects of ischaemia at a cellular level have been studied. ${ }^{31}$ Given the pivotal role of the NMDA receptor in the cellular derange- ments induced by ischaemia it is unsurprising that much attention has been focused on its regulation.

While many of the non-competitive NMDA antagonists used have shown substantial benefit in terms of reducing infarct size in experimental models, they have been unsuitable for clinical use because of their side effects. They block the NMDA receptor in a fashion similar to phencyclidine (angel dust) and can cause paranoia, hallucinations, agitation, or a decrease in conscious level. ${ }^{32}$ One of these agents, Aptiganel, has relatively fewer side effects and after encouraging results in a phase 11 study is currently under further investigation. ${ }^{33} \mathrm{~A}$ competitive blocker of the glycine regulatory site on the NMDA receptor, ACEA-1201, has also shown significant benefit in early trials and appears to be free of significant unwanted effects. ${ }^{34}$

Of the agents working distant to the NMDA receptor lubeluzole is perhaps the most promising. Its mechanism of action involves both inhibiting the increase in extracellular glutamate concentrations and also inhibiting the nitric oxide synthetase pathway, which by production of intracellular nitric oxide contributes to ischaemic induced neuronal death. It has been evaluated in a clinical trial involving 232 patients. ${ }^{35}$ Patients receiving a low dose of lubeluzole showed a very significant improvement in 28 day mortality compared with placebo and functional outcome also appeared to be improved in survivors. However these benefits were not apparent in a higher dose group in which there was a significantly greater 28 day mortality compared with the placebo group. A larger trial of this drug is currently underway.

\section{Conclusion}

It is clear that the active management of stroke is an emerging discipline with many potential 
therapies still at an experimental stage. Rigorous design and conduct of trials of these agents can play a significant part in allowing those treatments of proved efficacy to reach clinical practice quickly.

Although thrombolysis has only been shown to be of benefit when started soon after symptom onset, the possibility of giving a neuroprotectant drug early, perhaps in the pre-hospital setting, which will prolong the viability of the ischaemic neurones until more definitive treatment can be given is one which considerably broadens their applicability.

Emergency physicians have a pivotal role in expediting the imaging and treatment of acute stroke patients. Liaison with local colleagues to formulate policies on management is essential. As clear treatment guidelines become available it is increasingly obvious that the necessity for urgent intervention will make the role of the emergency department a crucial one if outcomes are to be improved.

1 Sandercock PAG, Celani MG, Ricci S. The likely public health impact in Europe of simple treatment for acute ischaemic stroke. Cerebrovascular Disease 1992;2:236.

2 Whisnant JP. The decline of stroke. Stroke 1984;15:160-8.

Heiss WD, Graft R. The ischaemic penumbra. Curr Opin Neurol 1994;7:11-19.

4 Baron JC, von Kummer R, del Zoppo GJ. Treatment of acute ischemic stroke challenging the concept of a rigid and universal time window. Stroke 1995;26:2219-21.

5 Jorgensen L, Torvik A. Ischemic cerebrovascular diseases in an autopsy series, part II: prevalence, location, pathogenesis, and clinical course of cerebral infarct. Neurological $S$ ience 1969;9:285-320.

6 LodderJ, Krijne-Kubat B, Broekman J. Cerebral hemorrhagic infarction at autospy: cardiac embolic cause and the relationship to the cause of death. Stroke 1986;17:626-9.

7 Johnston KC, Haley EC Jr. Emergency imaging of the acute stroke patient. $\mathcal{F}$ Neuroimaging 1997;7:111-17. 8 Adams HP, Brott TG, Furlan AJ, et al. Guidelines for thrombolytic therapy for acute stroke: a supplement to the guidelines for management of pate

9 Moulin T, Cattin F, Crepin-Leblond T, et al. Early CT signs in acute middle cerebral artery infarction: predictive valve for subsequent infarct locations and outcome. Neurology 1996;47:366-75.

10 Hacke W, Kasate M, Fiechi C, et al. Intravenous thrombolysis with recombinant tissue plasminogen activator for acute hemispheric stroke. The European Cooperative Acute Study (ECASS). FAMA 1995;274:1017-25.

11 Fisher M, Prichard JW, Warach S. New magnetic resonance techniques for acute ischemic stroke. $\mathfrak{F A M A} 1$ 1995;274: 908-11.

12 Sandercock $P$, Willems $H$. Medical treatment of acute ischaemic stroke Lancet 1992:339:537-9.

13 Dorman PJ, Sandercock PAG. Considerations in the design of clinical trials of neuroprotective therapy in acute stroke. Stroke 1996;27:1507-15.
14 Markku K, Heikki P, Seppo S. Where and how should elderly stroke patients be treated? A randomized trial. Stroke 1995:26:249-53.

15 Adams HP Jr, Brott TG, Crowell RM, et al. Guidelines for the managment of patients with acute ischaemic stroke. A statement for healthcare professionals from a special
writing group of the Stroke Council, American Heart writing group of the Stroke Council
Association. Stroke 1994;25:1901-14.

16 Blood pressure management in acute stroke. Part 1: assessment of trials designed to alter blood pressure. Cochrane Database of Systematic Reviews.

17 Tissue plasminogen activator for acute ischemic stroke. The National Institute of Neurological Disorders and Stroke rt-Pa Stroke Study Group. N Engl f Med 1995;333:115817 .

18 Asplund K, Israelsson K, Schampi I. Haemodilution in acute ischemic stroke. Cochrane Database of Systematic Reviews.

19 Kiyoyuki Y, Camarata P, Spellman SR, et al. Optimal timing of hemodilution for brain protection in a canine model of focal cerebral ischemia. Stroke 1996;27:906-12.

20 Qizilbash N, Lewington SL, Lopez-Arrieta JM. Corticosteroids following acute presumed ischaemic stroke. Cochrane Database of Systematic Reviews.

21 International Stroke Trial Collaboration Group. The International Stroke Trial (IST): a randomised trial of aspirin subcutaneous heparin, both or neither among 19435 patients with acute ischaemic stroke. Lancet 1997;349: 1569-81.

22 Bousser MG. Aspirin or heparin immediately after stroke. Lancet 1997:349:1564-5.

23 CAST (Chinese Acute Stroke Trial) Collaborative Group. Randomised placebo-controlled trial of early aspirin use in 20000 patients with acute ischaemic stroke. Lance 1997;349:1641-9.

24 Kay R, Wong KS, YuYL, et al. Low-molecular-weight heparin for the treatment of acute ischaemic stroke. N Engl 7 Med 1995;333:1588-93.

25 Massey E, Biller J, Davis JN, et al. Large-dose infusions of heparinoid Org 10172 in ischemic stroke. Stroke 1990;21: 1289-92.

26 The Prolyse in Acute Cerebral Thromboembolisim Trial (PROACT): results of $6 \mathrm{mg}$ dose tier. Stroke 1996;27:164. 27 Anonymous. Pro-urokinase beneficial in stroke. Scrip 2102: 13 February, 1996:20.

28 Multicenter Acute Stroke Trial-Europe Study Group. Thrombolytic therapy with streptokinase in acute ischemic stroke. N Engl ₹ Med 1996:335:145-50.

29 Multicenter Acute Stroke Trial-Italy (MAST-I) Group. Randomised controlled trial of streptokinase, aspirin, and combination of both in treatment of acute iuschaemic combination of both in treatment

30 Donnan GA, Davis SM, Chambers BR, et al for the Australian Streptokinase (ASK) Trial Study Group. Streptokinase for acute ischemic stroke with relationship to time of administration. $\mathcal{F} A M A$ 1996;276:961-6.

31 Dorman PJ, Counsell CE, Sandercock PAG. Recently developed neuroprotective therapies for acute stroke: a qualitative systematic review of clinical trials. Central Nervqualitative systematic review of clinistem Drugs 1996;5:457-74.

32 Muir KW, Lees KR. Clinical experience with excitatory amino acid antagonist drugs. Stroke 1995;26:503-23.

33 Anonymous. Clinical trials update. Scrip 2150: 30 July, 1996:19.

34 Anonymous. Clinical trials update. Scrip 2182: 19 November, 1996:27.

35 Diener HC, Hacke W, Hennerici M, et al for the Lubeluzole International Study Group. Lubeluzole in acute ischemic stroke. A double-blind, placebo-controlled phase II trial. Stroke 1996;27:76-81. 